\title{
EPIGRAFIA LATINA, UMA ABORDAGEM INTERDISCIPLINAR DO MUNDO ANTIGO*
}

\author{
Pedro Paulo A. Funari ${ }^{1}$ \\ Renata S. Garraffoni²
}

A primeira conferência sobre Instrumenta Inscripta Latina foi realizada em Sopianae (Pécs, Hungria), no começo dos anos 1990. Aproximadamente 13 anos mais tarde, a segunda conferência internacional aconteceu em Klagenfurt, Áustria, no início de maio de 2005 (figura 1 e 2). O evento foi organizado pela Academia de Ciência Austríaca e pelo Landermuseum Kärnten, sob o patrocínio da Association Internationale de l'Épigraphie Grecque et Latine, para discutir a epigrafia latina vulgar e o papel de novas tecnologias, tais quais bancos de dados eletrônicos. O encontro reuniu uma série de estudiosos de diversos países, com diferentes abordagens e encorajou o debate teórico e metodológico.

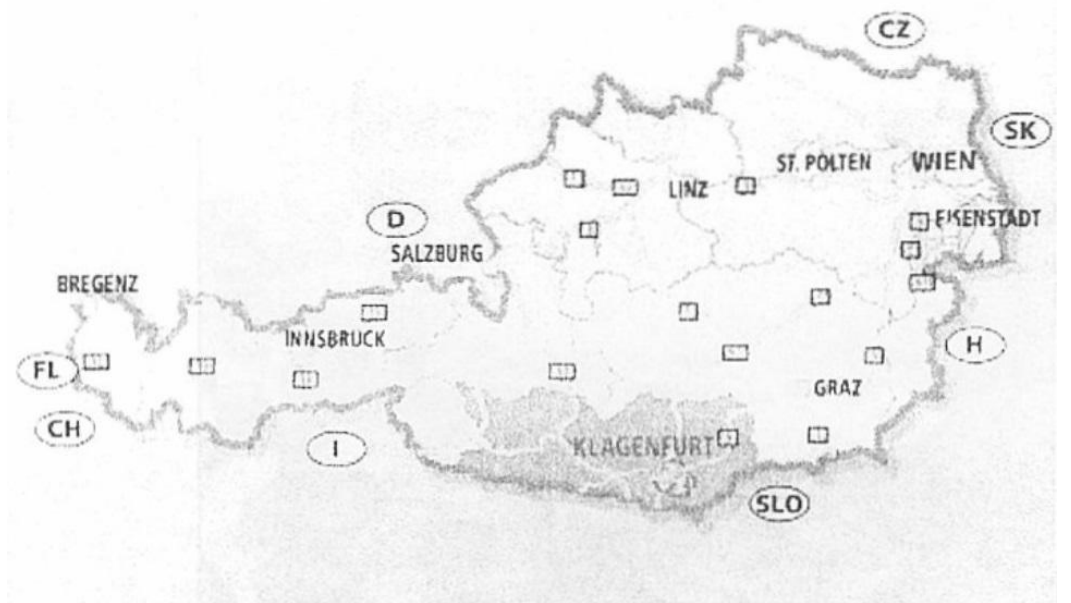

Fig. 1.

\footnotetext{
* Artigo originalmente publicado como FUNARI, P. P. A.; GARRAFFONI, R. S. Latin Epigraphy, an interdisciplinary approach to the ancient world. Clássica, São Paulo, v. 17/18, n. 17/18, 2004/2005, pp. 311 - 322. Tradução: Tais Pagoto Bélo e Otávio Luiz Vieira Pinto.

${ }^{1}$ Professor Titular, Universidade Estadual de Campinas, Campinas, Brasil. E-mail: ppfunari@uol.com.br

2 Professora Associada, Universidade Federal do Paraná, Curitiba, Brasil. E-mail: resenna93@gmail.com
} 

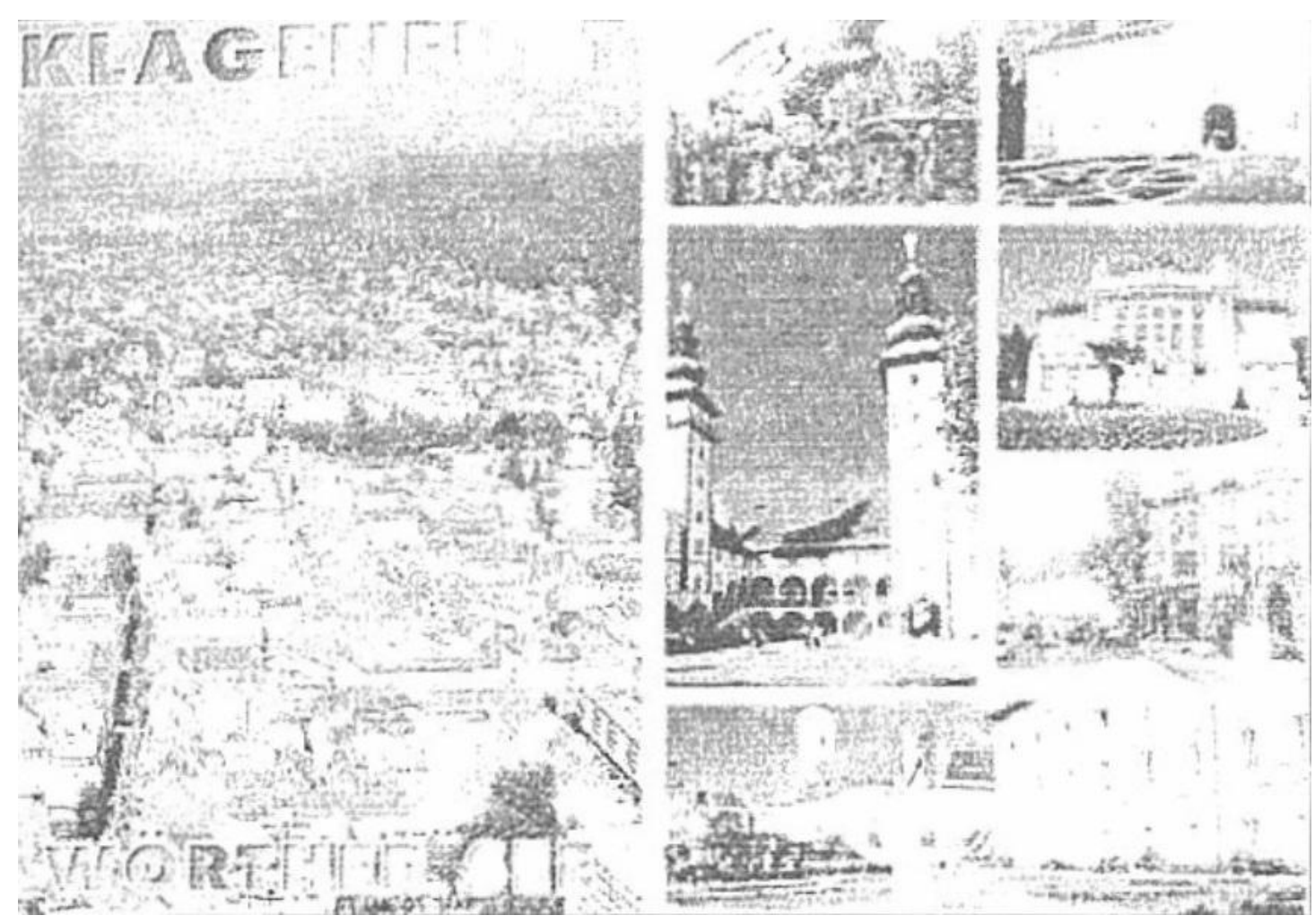

Fig. 2.

O estudo das inscrições latinas populares, a instrumenta inscripta Latina, tem uma longa tradição, desde o início dos Corpora das inscrições no século XIX, mas tem se desenvolvido especialmente nas últimas décadas. Isto é devido a vários motivos, não apenas pelo achado arqueológico de milhares de inscrições em amphorae, mortaria, tábuas, ladrilhos, vidros, tesserae nummulariae, couro, louça samian, entre outros, mas também pelo fato de, recentemente, ter havido uma atenção crescente à vida comum das pessoas na epistemologia histórica e nas discussões teóricas da Arqueologia e Antropologia. Esses movimentos explicam a criação de uma comissão internacional ${ }^{3}$ sobre a epigrafia latina vulgar e as conferências sobre o mesmo assunto, que provaram ser um grande sucesso na promoção de um entendimento mais amplo dos aspectos econômicos, sociais e culturais do mundo antigo. A Comissão tem estabelecido como tarefa principal a ponderação sobre características especificas da epigrafia latina popular, considerando que haverá especial atenção a este assunto no próximo Congresso sobre Epigrafia Antiga4, que ocorrerá em Oxford, em 2007 (figura 3).

\footnotetext{
${ }^{3}$ Os três presidentes atuais são M. Hainzmann, J. Remesal and C. Zaccaria.

4 XIII Congresso Internacional de Epigrafia Grega e Latina.
} 


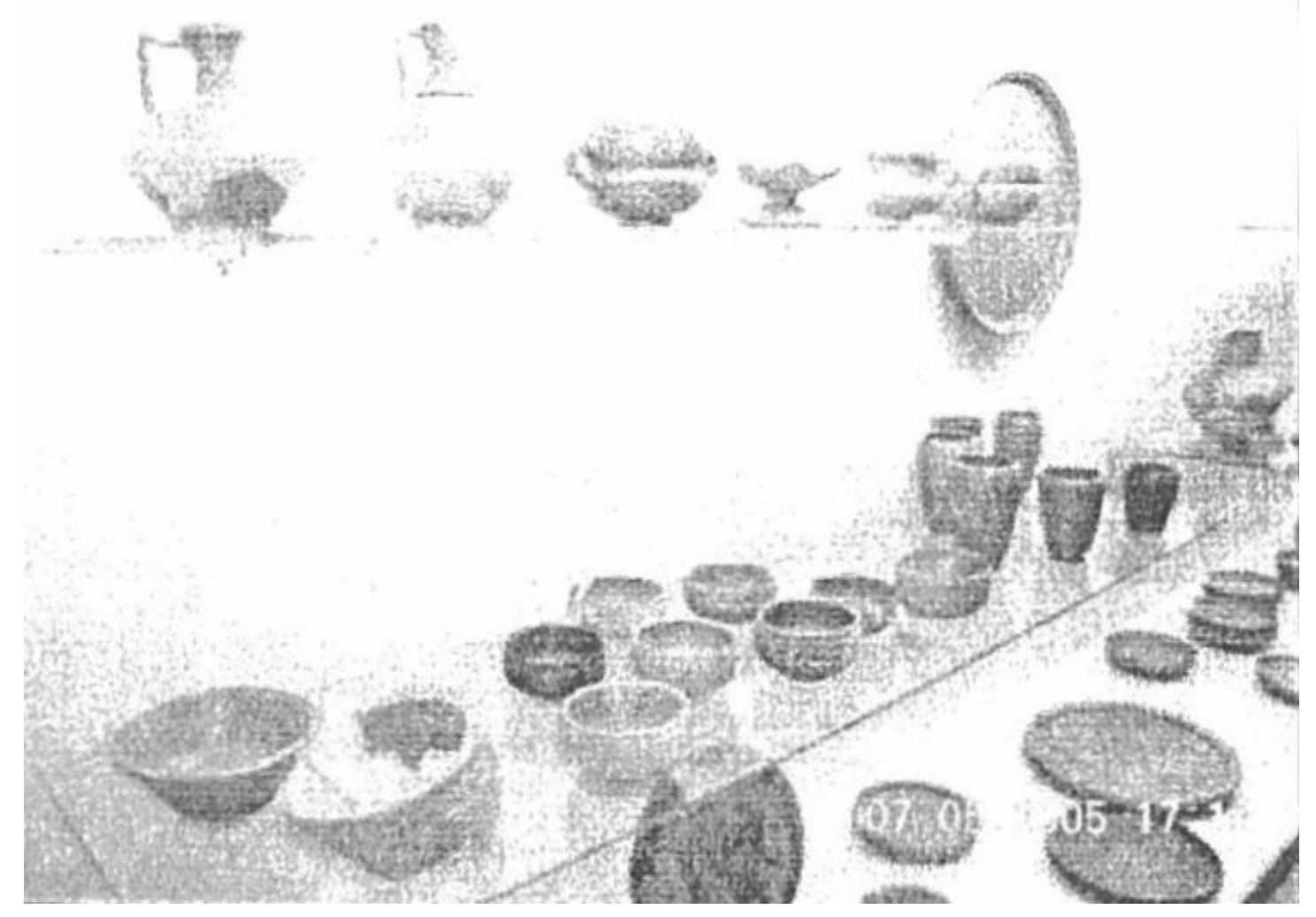

Fig. 3.

A conferência foi concebida como um workshop acadêmico, com a participação de um número limitado de conferencistas, possibilitando a todos os pouco mais de 40 participantes a não apenas lerem suas apresentações, mas também a participarem do debate das outras apresentações. A maioria dos apresentadores expuseram em alemão, e consequentemente, a maioria das discussões foram nessa língua. Entretanto, também houve apresentações e debates em italiano, inglês e francês durante as sessões. Neste evento havia palestrantes da Áustria, Alemanha, Itália, Espanha, Brasil, Bulgária, Eslovênia, França, Hungria, Luxemburgo, Reino Unido e epigrafistas com formações acadêmicas variadas, a maioria historiadores e arqueólogos, mas também latinistas.

Como parte da Conferência, os participantes visitaram os sítios arqueológicos romanos na região, especificamente Verunum (figuras 4, 5, 6), Magdalensberg (figuras 7, 8, 9, 10, 11, 12) e Teurnia (figuras 13, 14, $15,16)$, onde os partícipes tiveram expressivas palestras acadêmicas com os estudiosos locais nos próprios sítios, exibições e museus. $\mathrm{O}$ professor Hainzmann presidiu a abertura e o fechamento das sessões como o melhor anfitrião. Os professores sêniores, como Pedro Paulo Funari, Manfred Hainzmann, Marc Mayer, José Remesal, e Claudio 
Zaccaria presidiram as sessões e contribuíram para uma discussão muito proveitosa sobre as questões tratadas em cada debate.

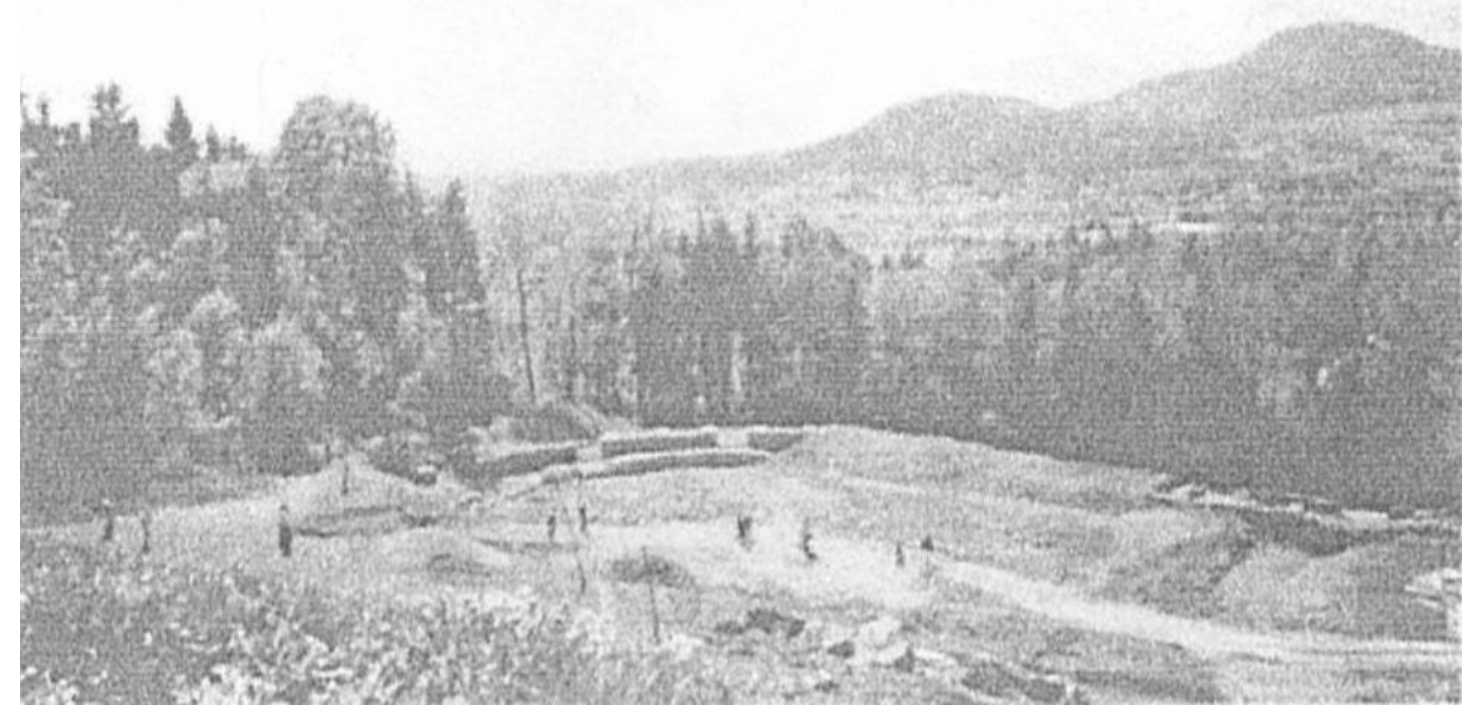

Fig. 4.

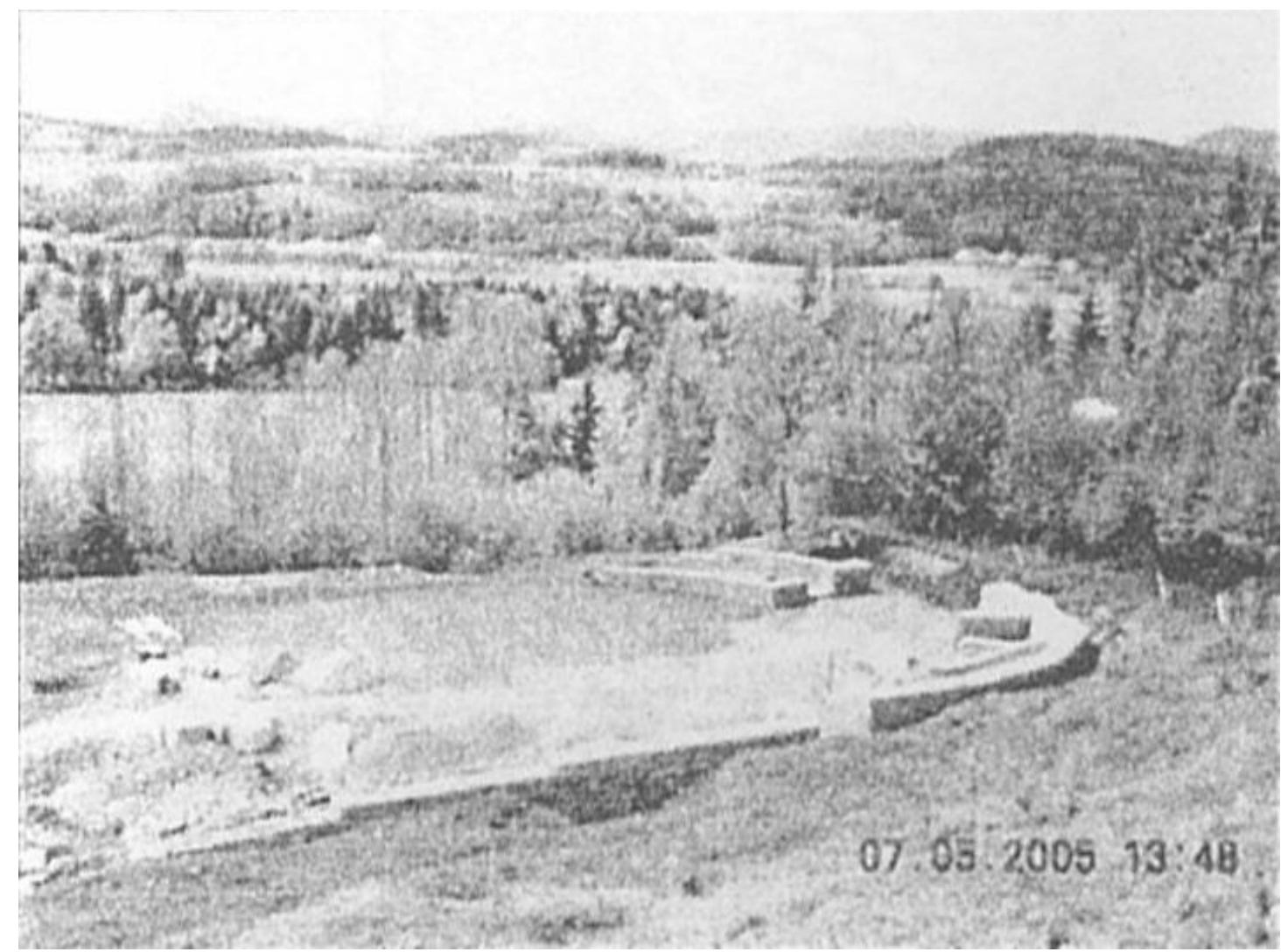

Fig. 5. 


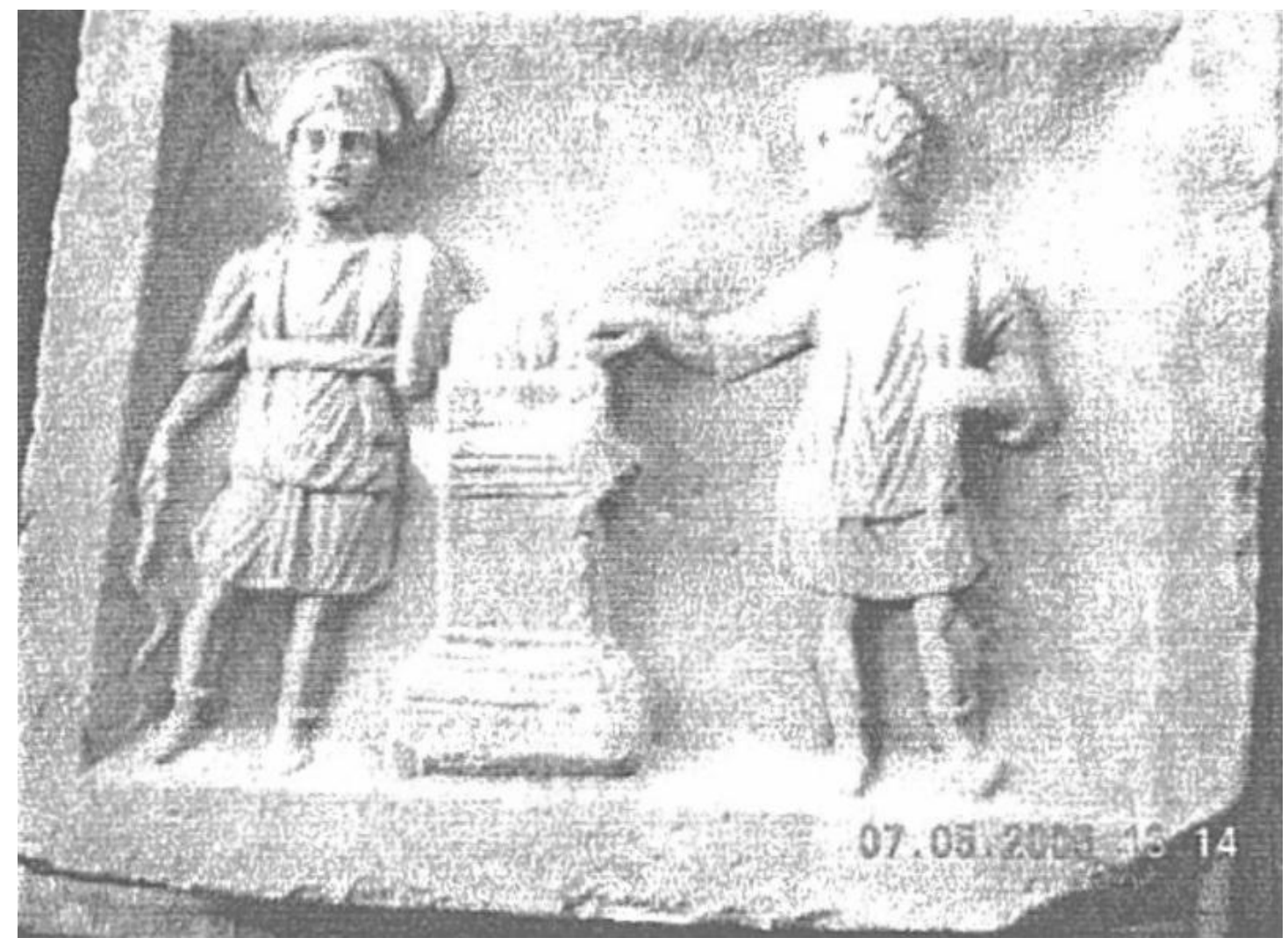

Fig. 6.

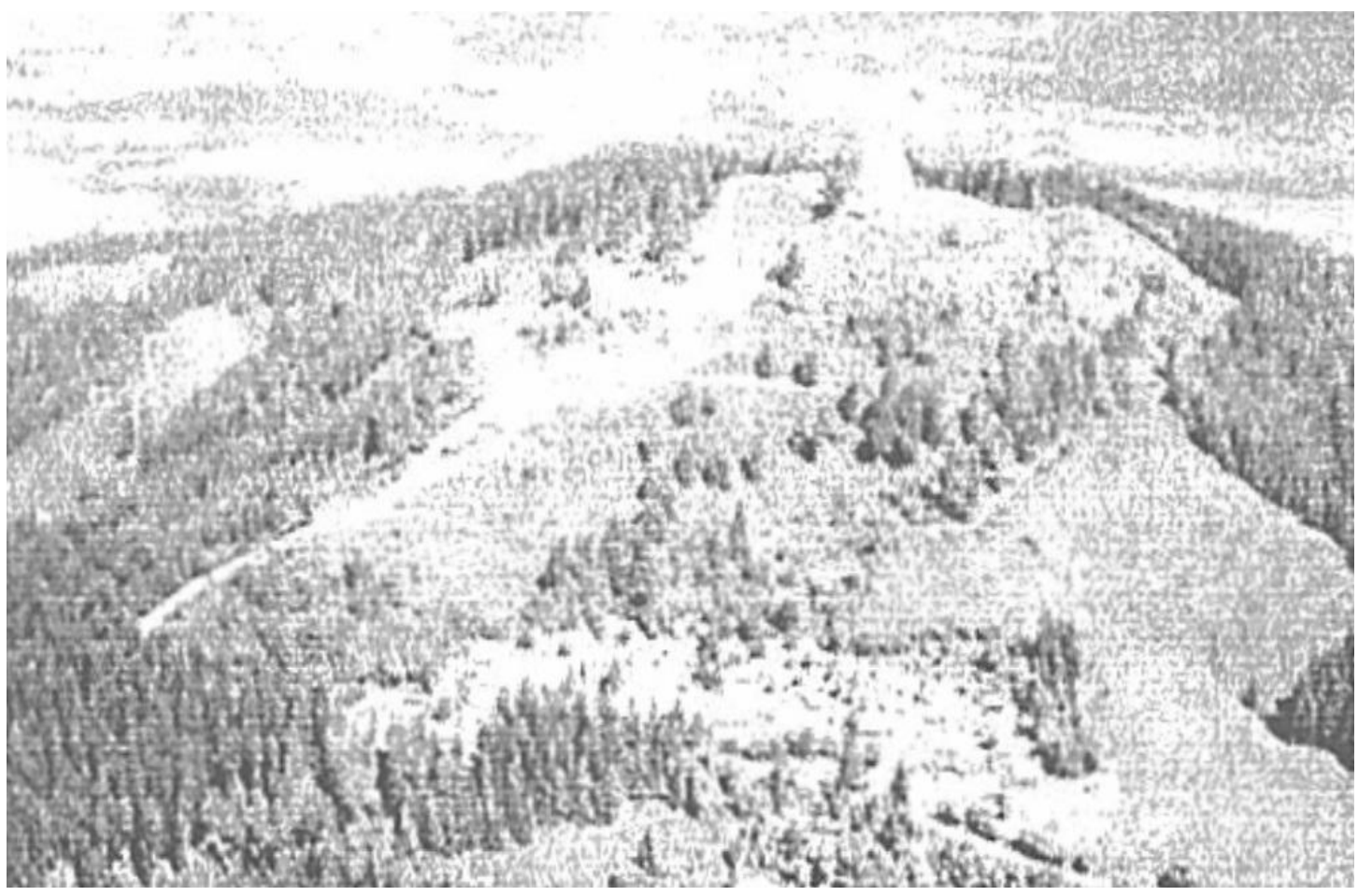

Fig. 7. 


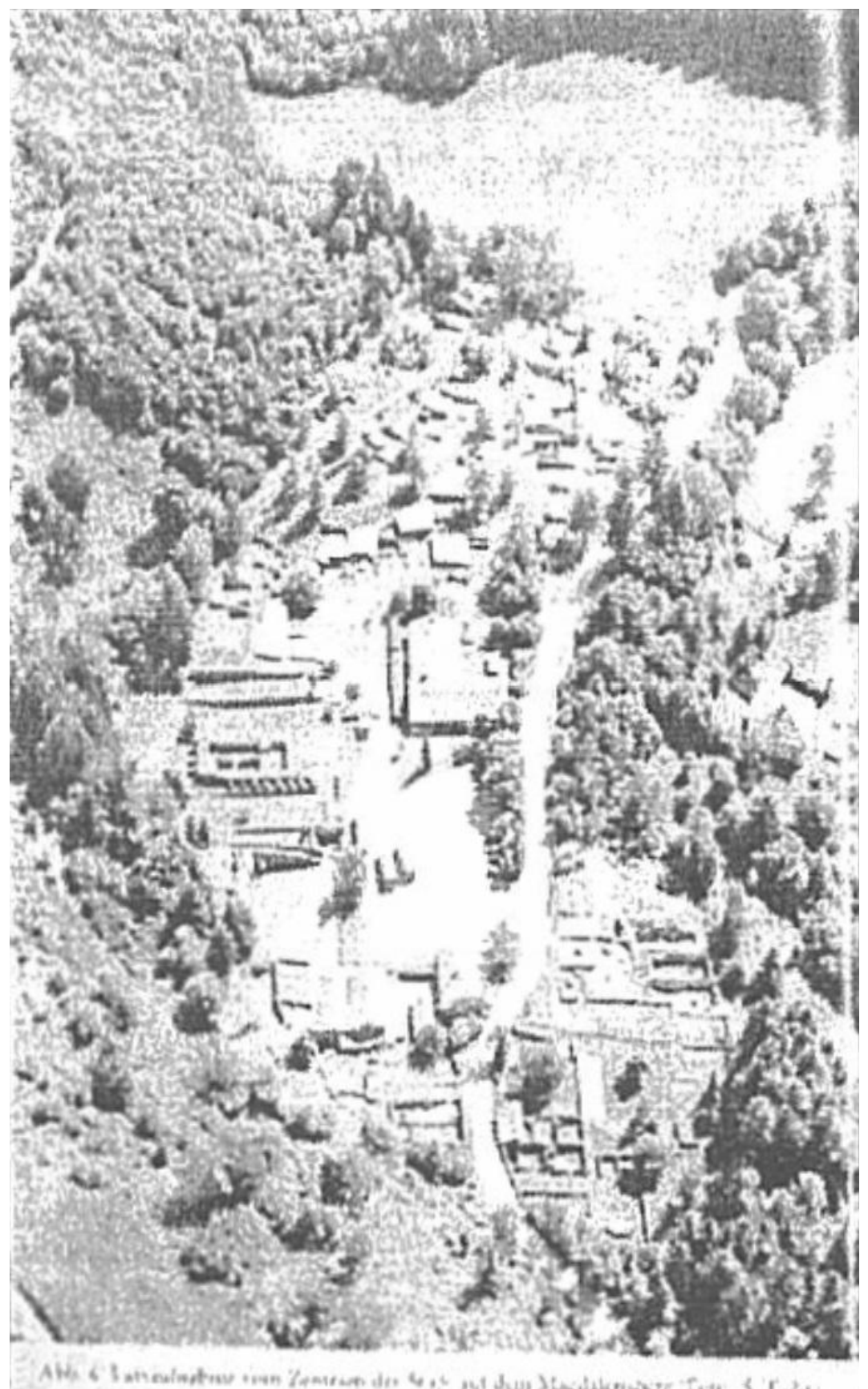

Fig. 8. 


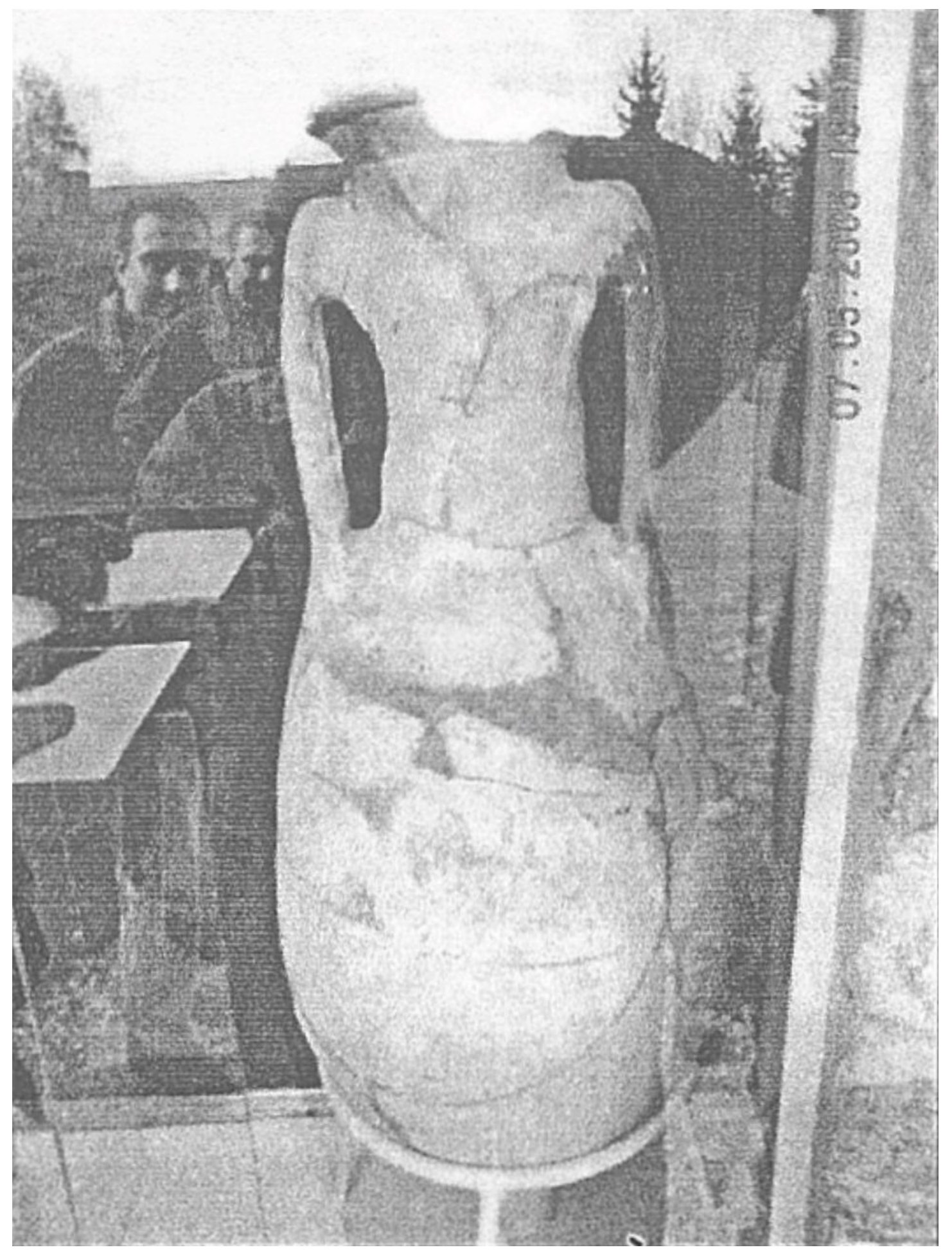

Fig. 9. 


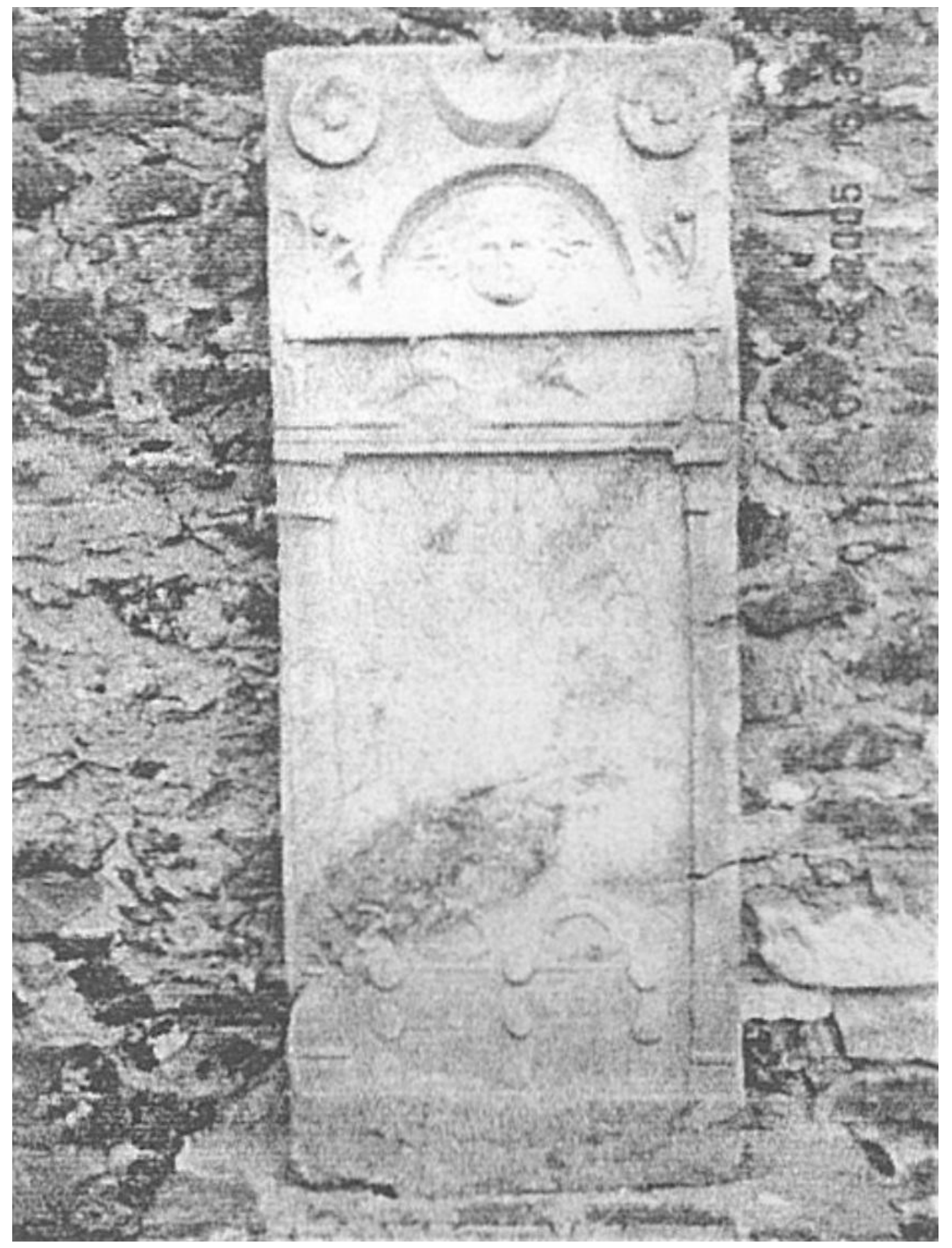

Fig. 10. 


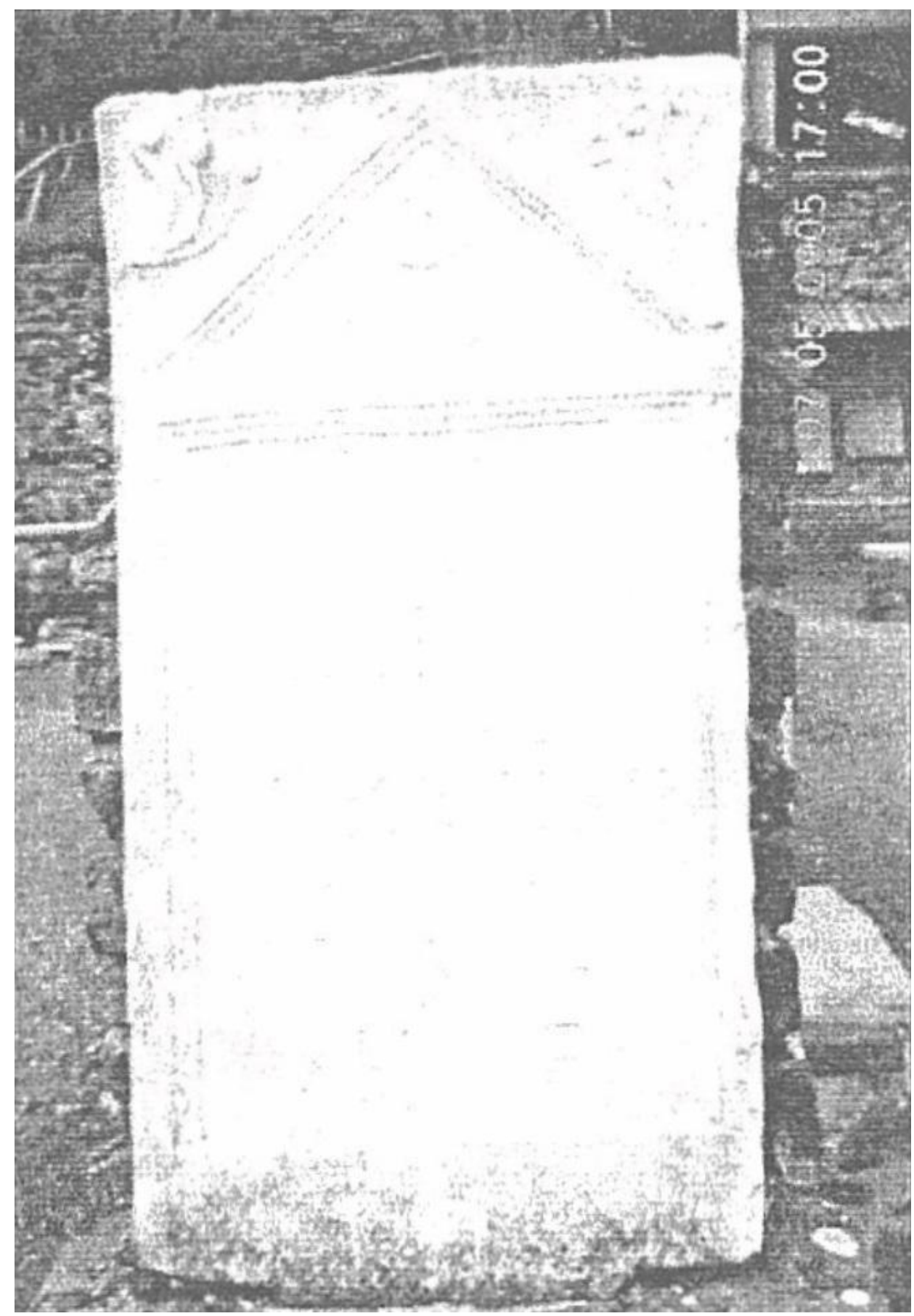

Fig. 11. 


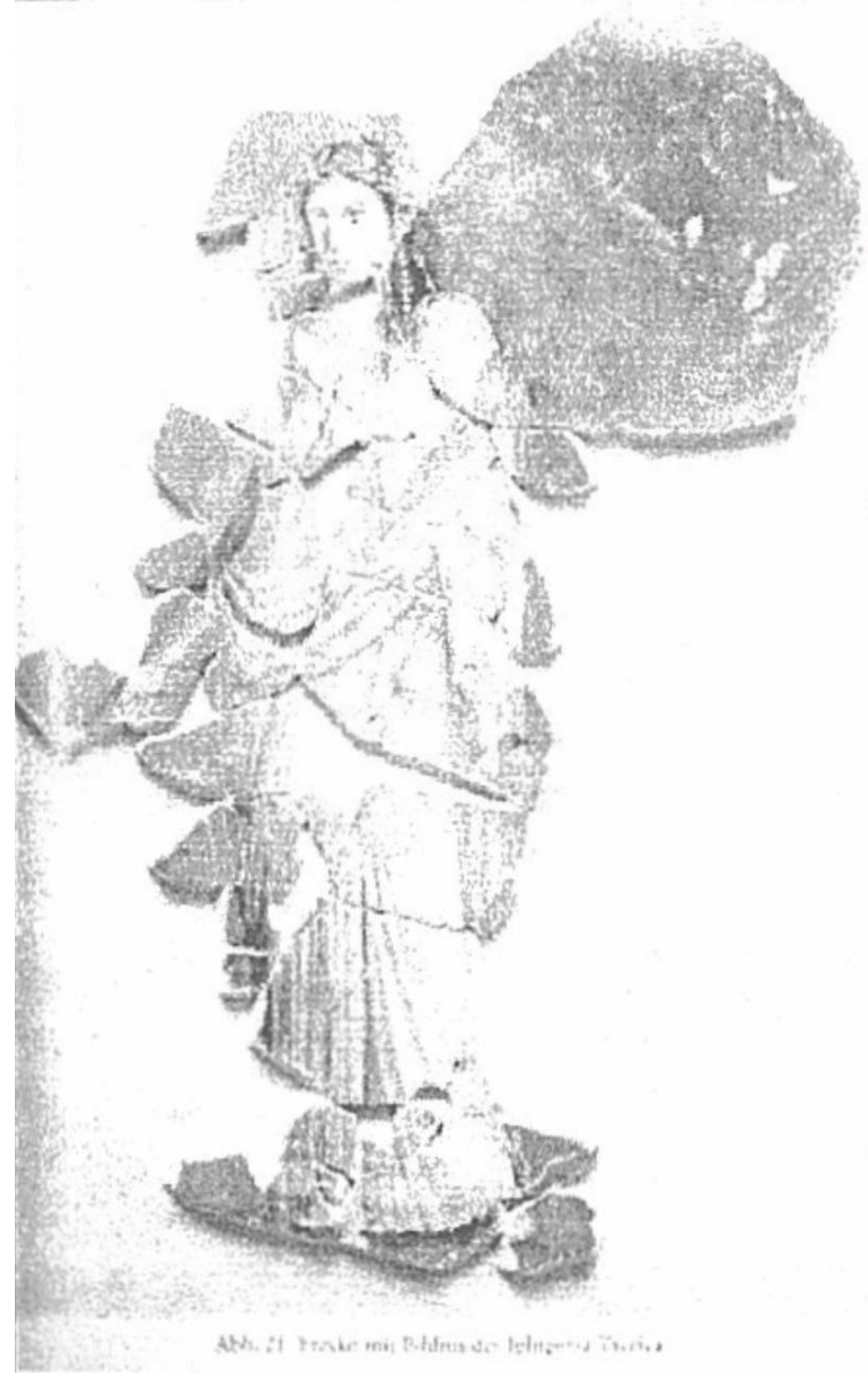

Fig. 12. 


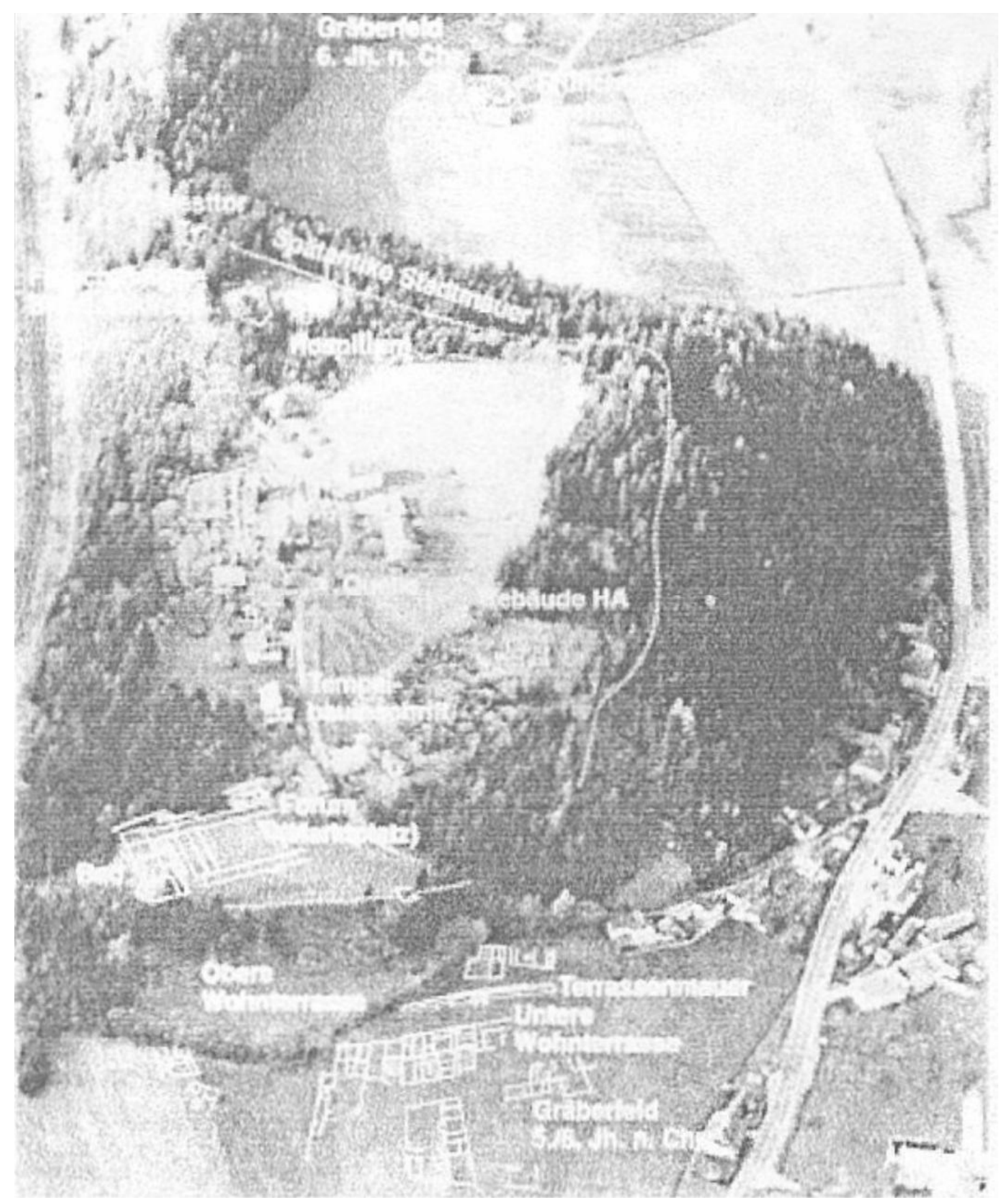

Fig. 13. 


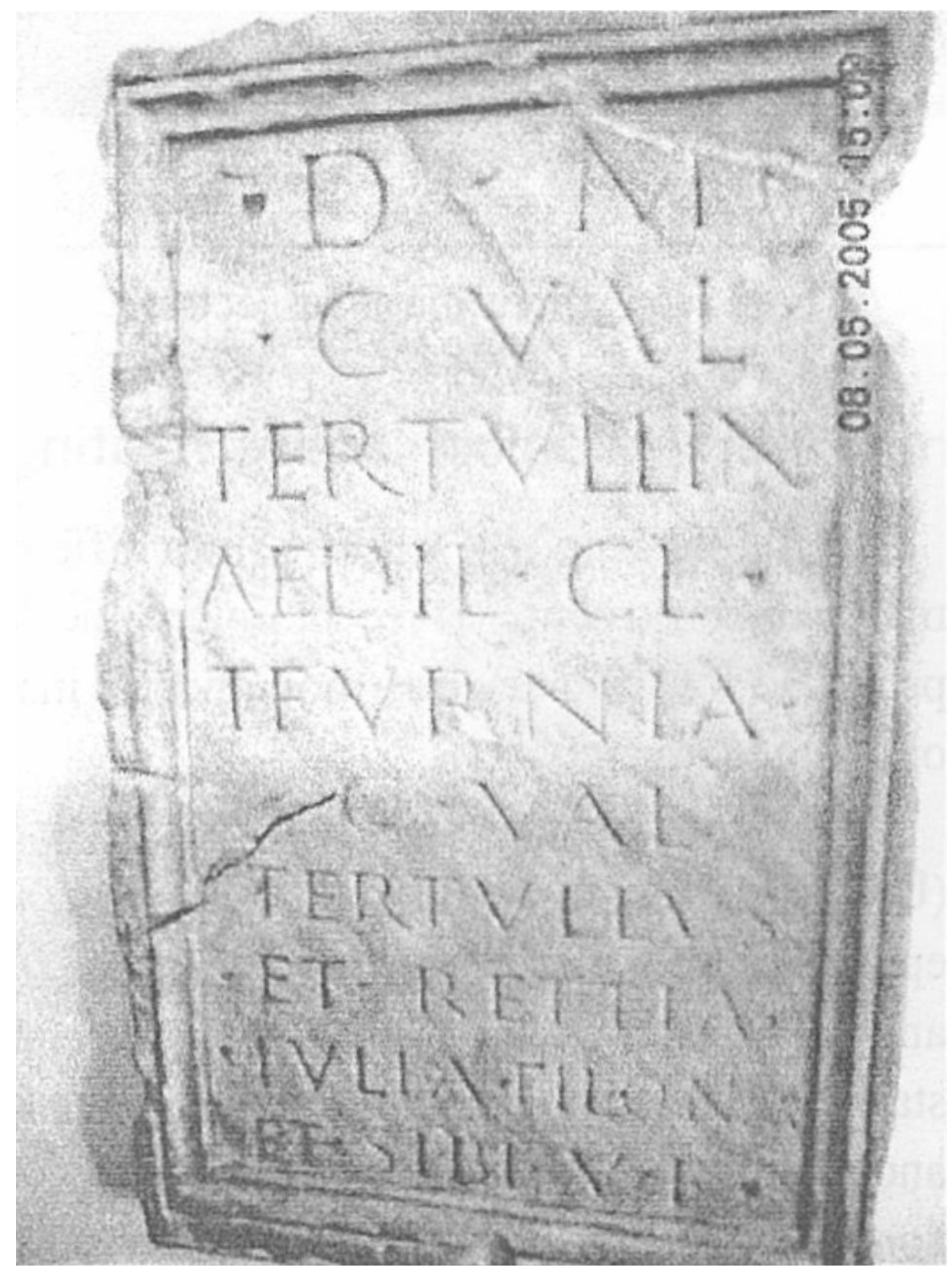

Fig. 14. 


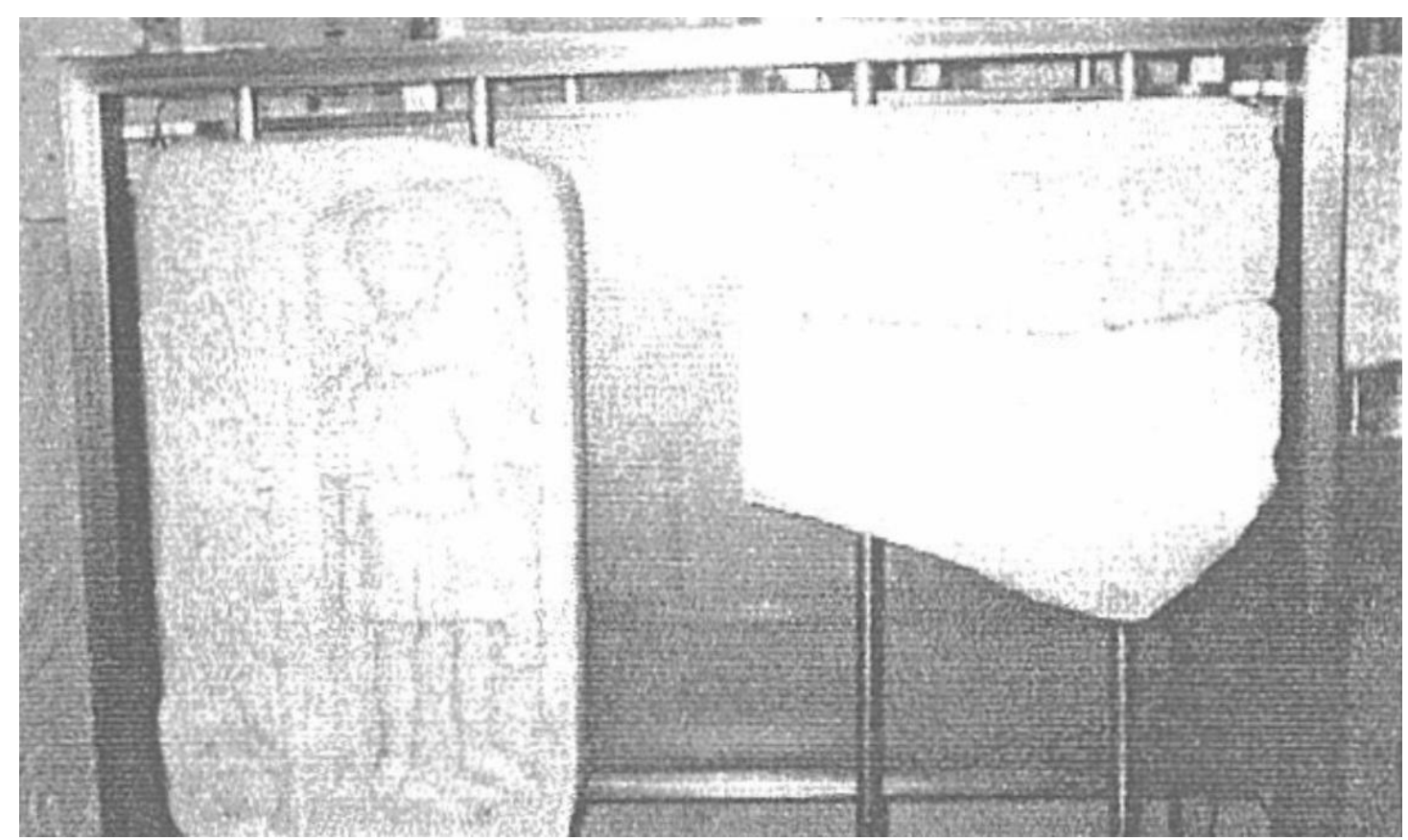

Fig. 15.

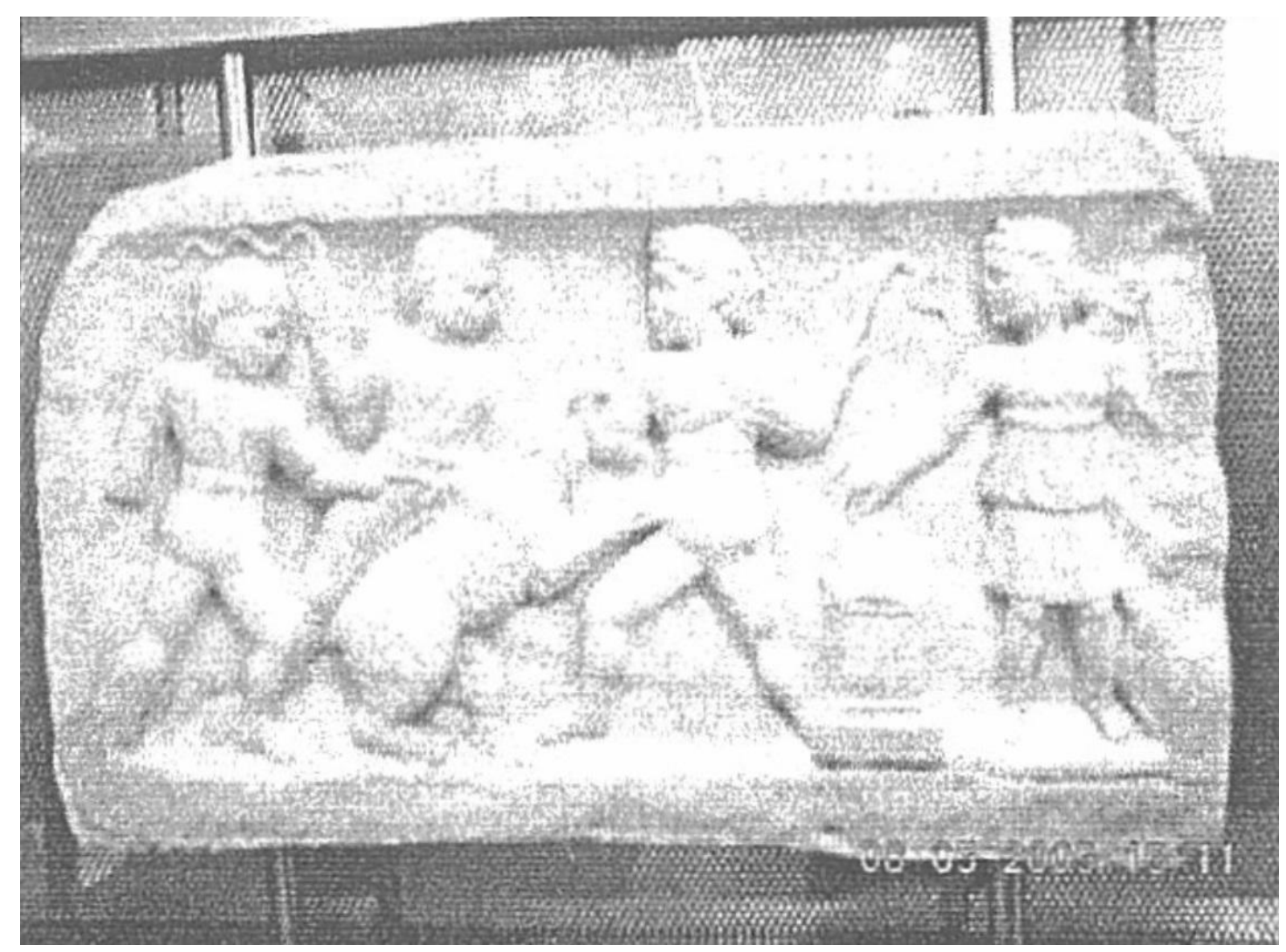

Fig. 16. 


\section{Questões metodológicas relacionadas ao gerenciamento de banco de dados}

Nessas sessões, acadêmicos de diferentes universidades debateram o papel da informática na construção atual de bancos de dados sobre Epigrafia. Diferentes tipos de bancos de dados foram propostos para inscrições vulgares e monumentais, e os potenciais dessa nova tecnologia foram explorados.

O professor Remesal apresentou os bancos de dados que vêm desenvolvendo no CEIPAC (Universidade de Barcelona) nos últimos anos. Os membros do CEIPAC enfocam a epigrafia de ânforas e seus diferentes tipos de inscrição: impressão, tituli picti e grafite ante e post coctarum. Cada inscrição é relacionada com diferentes aspectos, o que significa que cada impressão e grafite ante e post coctarum estão relacionados com a produção da ânfora e seu conteúdo, enquanto os tituli picti são ligados à comercialização de diferentes conteúdos (figuras 17, 18).

Atualmente, existem mais de 20000 inserções no banco de dados do CEIPAC. Como este catálogo esta na internet, o professor Remesal enfatizou que essa tecnologia permite que estudiosos introduzam novas evidências encontradas em escavações arqueológicas. Essa facilidade demonstra a intenção do projeto, a qual é criar um grupo internacional sob o patrocínio da Union Académique Internationale.

O professor Zaccaria (Universidade de Trieste) apresentou um banco de dados que tem sido desenvolvido pelo Laboratorio di Epigrafia di Trieste. Este banco de dados também focaliza o instrumentum domesticum, embora o tópico principal seja as estampas dos ladrilhos de Regio X. O enfoque metodológico é relacionado a um projeto anterior, que produziu um catálogo de lápides e que era conectado também ao projeto EAGLE (Arquivos Eletrônicos de Epigrafia Grega e Latina). Este banco de dados, como o CEIPAC, é um sistema digital, que também permite aos pesquisadores comparar diferentes tipos de evidências, assim como buscar por referencias bibliográficas.

Por último, mas não menos importante, o professor Hainzmann (Universidade de Graz) apresentou outro tipo de banco de dados. Ele focou nas inscrições monumentais e discutiu abordagens metodológicas para sua transcrição para o banco de dados. O professor Hainzmann também enfatizou que o sistema eletrônico e as novas tecnologias são instrumentos úteis que tem incitado diferentes tipos de diálogos entre 
acadêmicos, assim como também desafiá-los em uma perspectiva global.

Apesar dos três bancos de dados possuírem temas (ânforas, ladrilhos e inscrições monumentais) e abordagens metodológicas diferentes, os debates se referem a um esforço comum desses estudiosos e seus grupos em compartilhar informações e trabalhar dentro de uma perspectiva internacional.

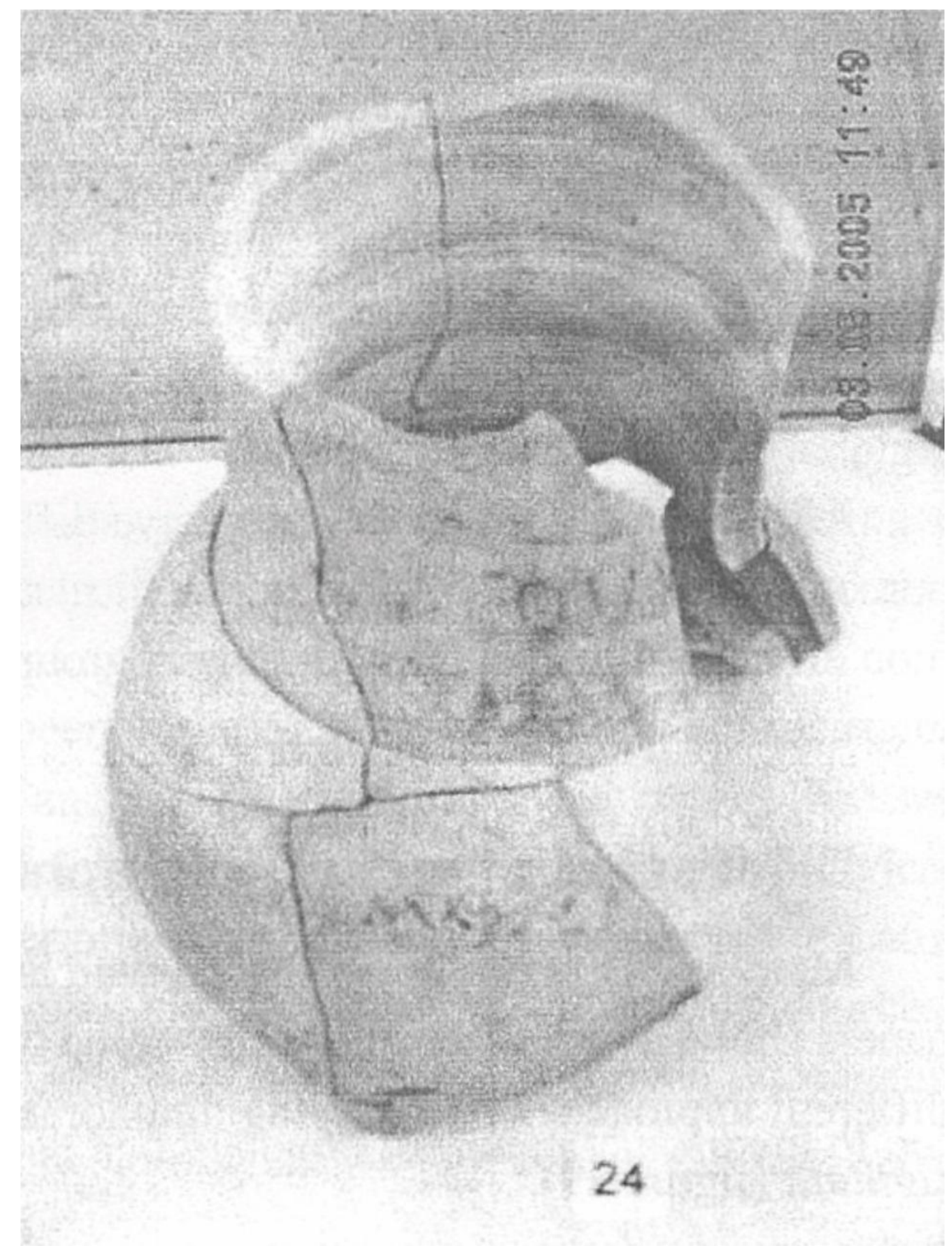

Fig. 17. 


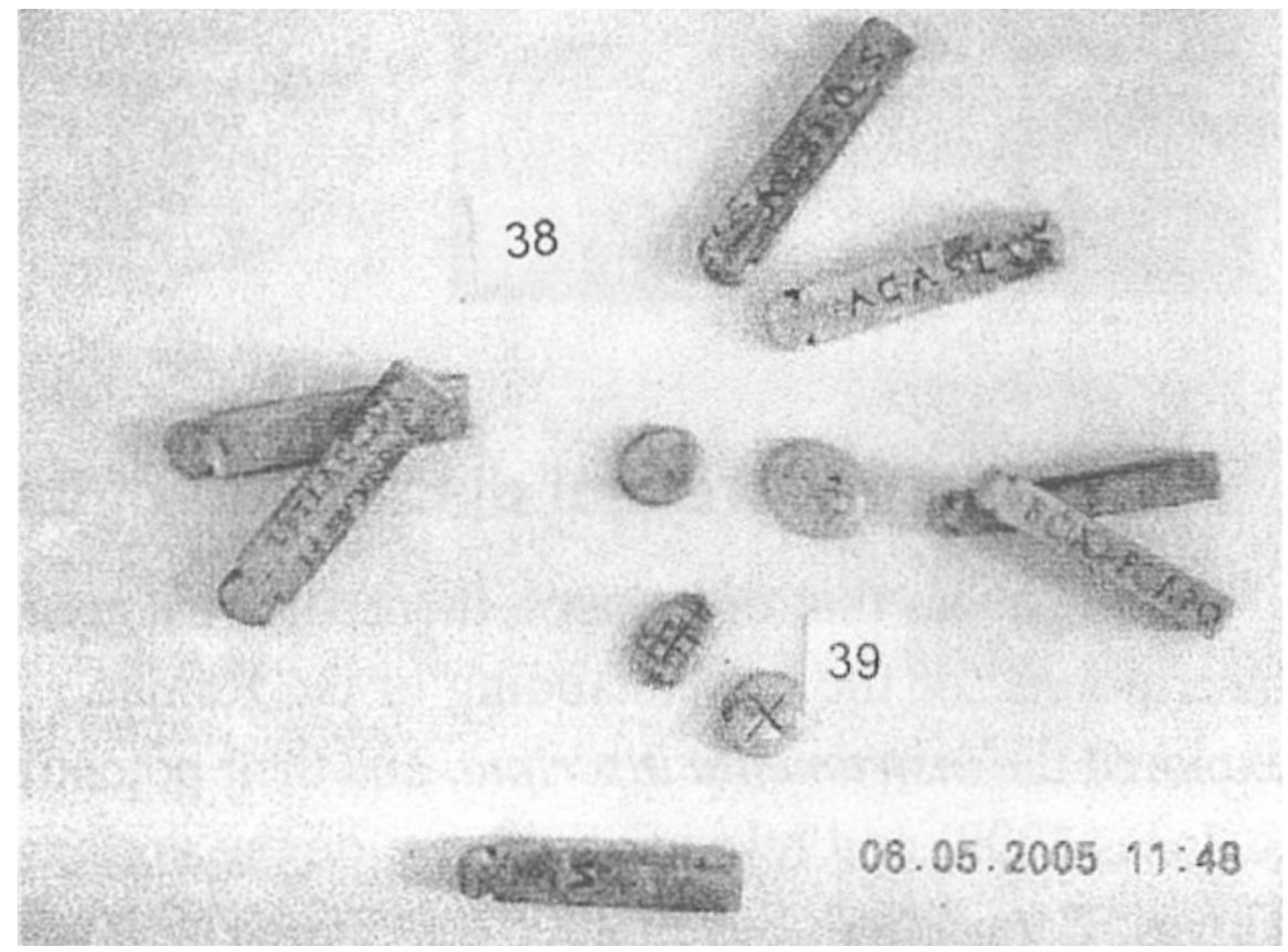

Fig. 18.

Debate sobre a evidência epigráfica recente

Muitos acadêmicos apresentaram suas pesquisas sobre diferentes tipos de inscrições. Essas apresentações mostraram novos registros que vieram à luz nas últimas escavações, assim como os distintos temas em relação ao estudo de ânforas, tábuas, ladrilhos, vidros, couro e terra sigillata (figura 19).
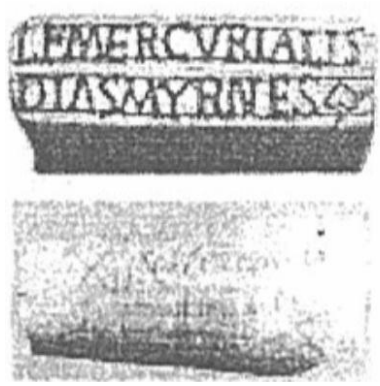
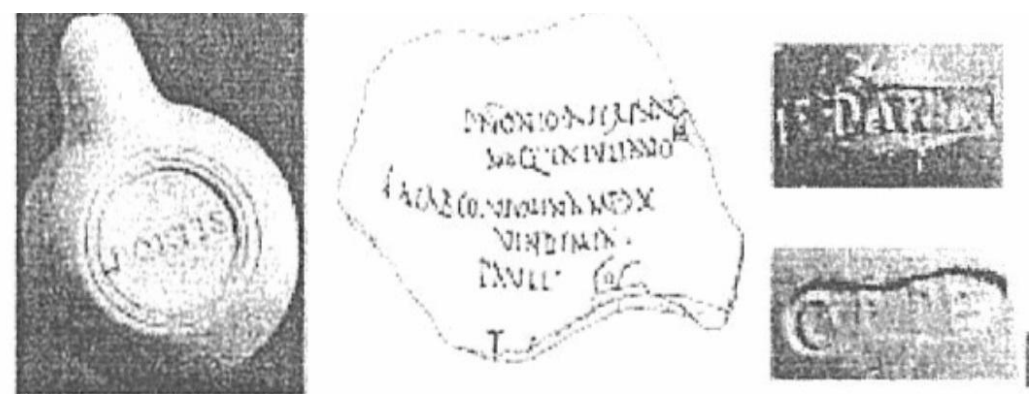

Fig. 19. 


\section{Em profundidade, debate teórico do modelo interpretativo}

Os artigos que chamaram a atenção para a discussão teórica realçaram a importância das inscrições para o entendimento da economia e sociedade romana. Os autores exploraram a instrumenta inscripta, e seu potencial enquanto evidências independentes (cf. Funari, Hall \& Jones, 1999) e relevantes sobre o mundo antigo, como um discurso material (cf. Funari, Zarankin \& Stovel, 2005).

O discurso de abertura de Geza Alföldy, sobre a importância das inscrições para o entendimento do mundo romano, resumiu o caráter geral da conferência, enfatizando o papel fundamental desempenhado pelas inscrições na formação da vida social em Roma, particularmente aquelas em artefatos comuns. Duas décadas atrás, em seu já clássico Roman Social History, Alföldy propôs que não era mais possível pensar sobre História Antiga sem a Arqueologia, e ele provou estar certo, pois as evidências arqueológicas multiplicaram-se desde então, reformulando tanto nossa disciplina de Estudos Clássicos, quanto nossa compreensão ampla do papel desempenhado pela cultura material na formação, não apenas da vida antiga, mas também da nossa percepção moderna do mundo antigo. A cultura material não é simplesmente um produto da sociedade, ela é integrante à esta, e os resquícios arqueológicos são uma parte dessa entidade que está junto conosco no presente. As inscrições populares não são nem uma reflexão da literatura antiga, nem sua ilustração (Thomas, 2005: 15, 25), elas constituem a evidência mais relevante e independente dos antigos. As inscrições vulgares nos possibilitam discutir sobre as relações econômicas no mundo antigo, as quais, de outra maneira, foram apenas mencionadas rapidamente pelos autores antigos. Os carimbos das ânforas, inscrições pintadas e grafites têm sido essenciais para se repensar a vida econômica antiga e para questionar modelos interpretativos fundamentados em leituras normativas da literatura clássica.

Os instrumenta inscripta também têm sido importantes para uma compreensão profunda da abundância social e cultural dos aspectos da vida desse período, mesmo em relação ao uso da língua latina, muitas vezes, enganosamente, considerada como um assunto exclusivamente filológico. Durante a conferência, muitas inscrições demonstraram os usos da língua latina no cotidiano, os quais são, surpreendentemente, diferentes daqueles da língua oficial, ou seja, do Latim Clássico das fontes literárias. Para finalizar, a atmosfera aberta do debate acadêmico provou, mais uma vez, a importância da cooperação internacional e do diálogo para o avanço do nosso conhecimento sobre o passado. 


\section{Agradecimentos}

Nós gostaríamos de agradecer por todos aqueles que participaram da conferência, em particular aos colegas de pesquisas do CEIPAC, Universidade de Barcelona, Jose Remesal, Antonio Aguilera e Pero Berni. Nós também devemos lembrar do suporte institucional do Centro de Estudos Estratégicos, NEE UNICAMP, FAEP UNICAMP, CNPq e UFPR. A responsabilidade pelas ideias é nossa, pelas quais somos os únicos responsáveis.

\section{Referências}

FUNARI, P. P. A.; HALL, M. \& JONES, S. 1999. Historical Archaeology, back from the edge. London and New York: Routledge.

FUNARI, P. P. A.; ZARANKIN, A. \& STOVE, E. 2005. Global Archaeology theories. New York: Prenum.

PICCOTTINI, G et VETTERS, H. 2003, Führer durch die Ausgrabungen auf dem Magdalensberg, Verlag des Landesmuseums für Kärnten, Klagenfurt.

THOMAS, J. 2005. Materiality and the social, Global Archaeology Theory, Contextual Voices and Contemporary Thoughts, P. P. Funair, A. Zarankin, Em Stovel, eds, New York, Kluwer Penum, 1118. 